\title{
Combined UV treatment and ozonation for the removal of by-product precursors in
} swimming pool water

\author{
Cheema, Waqas Akram; Kaarsholm, Kamilla Marie Speht; Andersen, Henrik Rasmus
}

Published in:

Water Research

Link to article, DOI:

10.1016/j.watres.2016.12.008

Publication date:

2017

Document Version

Peer reviewed version

Link back to DTU Orbit

\section{Citation (APA):}

Cheema, W. A., Kaarsholm, K. M. S., \& Andersen, H. R. (2017). Combined UV treatment and ozonation for the removal of by-product precursors in swimming pool water. Water Research, 110, 141-149.

https://doi.org/10.1016/j.watres.2016.12.008

\section{General rights}

Copyright and moral rights for the publications made accessible in the public portal are retained by the authors and/or other copyright owners and it is a condition of accessing publications that users recognise and abide by the legal requirements associated with these rights.

- Users may download and print one copy of any publication from the public portal for the purpose of private study or research.

- You may not further distribute the material or use it for any profit-making activity or commercial gain

- You may freely distribute the URL identifying the publication in the public portal 


\section{Accepted Manuscript}

Combined UV treatment and ozonation for the removal of by-product precursors in swimming pool water

Waqas A. Cheema, Kamilla M.S. Kaarsholm, Henrik R. Andersen

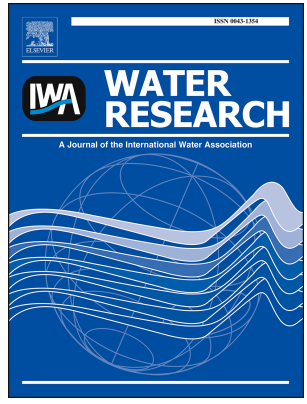

PII:

S0043-1354(16)30942-3

DOI:

10.1016/j.watres.2016.12.008

Reference: WR 12558

To appear in: Water Research

Received Date: 9 June 2016

Revised Date: 6 December 2016

Accepted Date: 7 December 2016

Please cite this article as: Cheema, W.A., Kaarsholm, K.M.S., Andersen, H.R., Combined UV treatment and ozonation for the removal of by-product precursors in swimming pool water, Water Research (2017), doi: 10.1016/j.watres.2016.12.008.

This is a PDF file of an unedited manuscript that has been accepted for publication. As a service to our customers we are providing this early version of the manuscript. The manuscript will undergo copyediting, typesetting, and review of the resulting proof before it is published in its final form. Please note that during the production process errors may be discovered which could affect the content, and all legal disclaimers that apply to the journal pertain. 


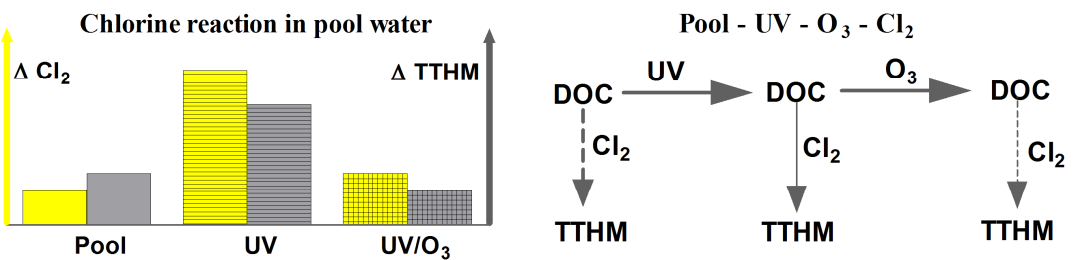




\section{Combined UV treatment and ozonation for the removal of by-}

\section{2 product precursors in swimming pool water}

3 Waqas A. Cheema ${ }^{1,2}$, Kamilla M. S. Kaarsholm ${ }^{1}$, Henrik R. Andersen ${ }^{1 *}$

$4 \quad{ }^{1}$ Department of Environmental Engineering, Technical University of Denmark, 2800 Kongens Lyngby, Denmark.

$5 \quad{ }^{2}$ National University of Sciences \& Technology, H-12, Islamabad 44000, Pakistan

6 *Corresponding author: henrik@ndersen.net

\section{Abstract}

8 Both UV treatment and ozonation are used to reduce different types of disinfection by-products

9 (DBPs) in swimming pools. UV treatment is the most common approach, as it is particularly

10 efficient at removing combined chlorine. However, the UV treatment of pool water increases

11 chlorine reactivity and the formation of chloro-organic DBPs such as trihalomethanes. Based on the similar selective reactivity of ozone and chlorine, we hypothesised that the created reactivity to chlorine, as a result of the UV treatment of dissolved organic matter in swimming pool water, might also be expressed as increased reactivity to ozone. Moreover, ozonation might saturate the chlorine reactivity created by UV treatment and mitigate increased formation of a range of volatile DBPs. We found that UV treatment makes pool water highly reactive to ozone. The subsequent reactivity to chlorine decreases with increasing ozone dosage prior to contact with chlorine. Furthermore, ozone had a half-life of $5 \mathrm{~min}$ in non-UV treated pool water whereas complete consumption of ozone was obtained in less than 2 min in UV treated pool water. The ozonation of UV-treated pool water induced the formation of some DBPs that are not commonly reported in this medium, in particular trichloronitromethane, which is noteworthy for its genotoxicity, though this issue was removed by UV treatment when repeated combined UV/ozone treatment interchanging with chlorination was conducted over a 24-hour period. The discovered reaction could form the basis for a new treatment method for swimming pools.

Keywords: Ozone, UV, swimming pool, trihalomethane, disinfection by-products 
27 Swimming pools are used for recreational activities, and it is necessary to disinfect swimming pool water in order to protect against infection by microbiological pathogens. Chlorine is the most commonly used disinfectant in swimming pool water. However, a general problem with maintaining chlorine concentrations for hygiene reasons is that the chlorine reacts continuously with organic matter in the water to form chloramines (combined chlorine) and chloro-organic by-products. A general concern about chloro-organic disinfection by-product (DBP) formation is the effect on human health, because some are carcinogenic (Richardson et al., 2007). There has been identified more than 100 DBPs in pool water (Richardson et al., 2010) where the most frequently investigated DBPs are chloramines, haloacetonitriles (HANs), haloacetic acids (HAAs) trihalomethanes (THMs), chloral hydrates and nitrosamines (Chowdhury et al., 2014; World Health Organisation, 2006). Both types of by-product can be reduced through water exchanges or different treatment methods. Combined chlorine concentration can be reduced with UV treatment via direct photolysis (PWTAG, 2009). It is an efficient way of removing chloramines to photolyse them with UV treatment in the return flow. Soltermann et al. (2014) reported that trichloroamine is the easiest of the combined chlorine species to be removed by UV.

A reduction in the combined chlorine level via medium pressure UV treatment has been reported by several full-scale studies (Beyer et al., 2004; Cassan et al., 2011, 2006; Kristensen et al., 2009). However, these studies do not agree regarding the effect of UV treatment on trihalomethane (THM) formation. An increase (Cassan et al., 2006) and decrease (Beyer et al., 2004) of THM formation has been reported in short-term full-scale studies. In contrast, Kristensen et al. (2009) observed no effect on THM levels in a swimming pool treated with UV in a long-term full-scale study. However, Liviac et al. (2010) illustrated that UV treatment might be beneficial for the reduction of genotoxicity and cytotoxicity in chlorinated swimming pool water. Hansen et al. (2013b) reported that photolysis is less important than volatilization for some volatile DBPs e.g. chloroform. Moreover, Zare Afifi and Blatchley. (2016) 
demonstrated that concentration of most volatile DBPs decreased with both MP and LP UV treatment. A recent laboratory study (Spiliotopoulou et al., 2015) reported that UV treatment appears to break down relative non-reactive organic molecules into smaller molecules which react quickly with chlorine and accelerated DBP formation but did not clearly increase the total amount formed. Ozone is difficult to use for pool water treatment, as there is a lack of a good reliable sensor for ozone detection in water and ozone cannot be allowed in the pool due to toxicity to swimmers. Different authors have mentioned ozone dosage of 1 ppm (Eichelsdörfer and Jandik, 1985), 0.8-1.2 ppm (Eichelsdörfer and Jandik, 1988) and 1.6 ppm (Hamil, 2011) for swimming pool water treatment. There is limited literature on the effect of ozonation on formation of chlorination DBPs in recirculated water, but knowledge about ozone and its kinetics can be found in the drinking water and wastewater ozonation literature (von Gunten, 2003). It has been found that the most common DBPs, along with nitrogen compounds and chloramine, react very slowly with ozone (Eichelsdörfer and Jandik, 1985); however, according to DIN standards for swimming pool water ozonation, a decrease (34-48\%) in chloroform formation potential can be achieved, depending on ozone contact time (Eichelsdörfer and Jandik, 1988). Alternatively, Glauner et al. (2005) achieved $12 \%$ absorbable organohalogen (AOX) reduction and 3\% reduction of total trihalomethane (TTHM) formation potential after 10 minutes of ozone oxidation compared with untreated pool water. An investigation of several pools (Lee et al., 2010) found that ozone/chlorine-treated swimming pools had lower levels of DBPs than chlorinated pools. A laboratory study (Hansen et al., 2016) reported that ozone reacts well with freshly added organic matter but slowly with organic matter that remains after extended chlorination. Additionally, it was reported that reaction with fresh organic matter decreases formation of volatile chlorination by-products, while a slow reaction with already chlorinated organic matter produces more volatile by-products with further chlorination.

Gaining an understanding of UV treatment followed by ozonation in swimming pools could help in designing more efficient treatment systems to minimise the occurrence of disinfection by-products. Thus, the aim of the current study is to investigate the effect of a combined 
80 treatment system on DBP formation. As both ozone and chlorine preferably react with

81 electrophilic groups in compounds (von Sonntag and von Gunten, 2012; White, 1992), we

82 hypothesise that reactivity to chlorine, created by the UV treatment of dissolved organic matter

83 in pool water, might also mean that there is increased reactivity to ozone and that ozonation

84 might remove the chlorine reactivity created by UV treatment. Therefore, we first performed an experiment to range-find the effect of swimming pool water UV activation on chlorine reactivity. Second, an experiment was carried out to characterise the effect of adding various doses of ozone to pool water, with or without UV pre-treatment, before chlorination to study the effect on chlorine reactivity and the formation of chlorination by-products. Finally, the possible effect on chlorination by-product formation was investigated by a repeated, combined UVozone treatment interchanged with chlorination (repeated cycles of UV followed by ozone with subsequent chlorination). Toxicity estimation was used to evaluate water quality.

\section{Material and methods}

\subsection{Reagents and standard analysis}

All chemicals and reagents were purchased from Sigma-Aldrich, Denmark. The experimental set-up for ozonation was based on a $20 \mathrm{~g} / \mathrm{h}$ ozone generator from O3-Technology AB (Vellinge, Sweden) which was supplied with dry oxygen gas. Generated ozone was dispersed through a diffuser in a collection bottle containing ultra-pure water, which was immersed in an ice bath so that ozone solubility would be maximised. To increase further the solubility of ozone, a manometer and valve were placed after the collection bottle, and a pressure of 1.4 barG was applied. Based on these experimental conditions, the concentration of ozone achieved in the stock solution was between 80 and $100 \mathrm{mg} / \mathrm{L}$.

Ozone was quantified via a colorimetric method using indigotrisulfonate (Bader and Hoigné, 1981). Reagents used were $0.5 \mathrm{M}$ phosphate buffer at $\mathrm{pH} 2$ and $1.00 \mathrm{~g} / \mathrm{L}$ potassium indigotrisulfonate dissolved in $20 \mathrm{mM}$ phosphoric acid and further description can be found in Hansen et al. (2016). Free and total chlorine in the collected pool water samples were measured 
106 using the colorimetric method based on the oxidation of diethyl-p-phenylenediamine (DPD),

107 with and without addition of iodide, while residual chlorine during the experiment was

108 determined by employing the colorimetric method, using 2, 2-azino-bis (3-

109 ethylbenzothiazoline)-6-sulfonic acid-diammoniumsalt (ABTS), as described by Pinkernell et

110 al. (2000). Non-volatile organic carbon in the pool water samples was quantified with a

111 Shimadzu ASI-V UVC/Persulphate analyser with a sample injection volume of $3 \mathrm{~mL}$. A

112 calibration curve was formed by using potassium hydrogen phthalate standards, with

113 concentrations ranging from 50 to $2000 \mu \mathrm{g} / \mathrm{L}\left(\mathrm{R}^{2}=0.9994\right)$. The method quantification limit

114 was $50 \mu \mathrm{g} / \mathrm{L}$. Non-volatile organic carbon is referred to herein as 'dissolved organic carbon'

115 (DOC).

\section{$116 \quad 2.2 \quad$ Pool water}

117 Pool water samples were collected from a public swimming pool and used for experiments on

118 the day of collection. The pool for water collection was the main practice basin in Gladsaxe

119 (Denmark). It is a typical public pool (temperature $26^{\circ} \mathrm{C}$, sand filter with flocculation and a side

120 stream activated carbon filter) with a hydraulic retention time (HRT) of 4 hours. The water in

121 the pool is not replaced besides the amount of water which is added due to evaporation and loss

122 during backwash of filters. Water for filling the pool is obtained from the public distribution

123 network, which comprises non-chlorinated groundwater. The $\mathrm{pH}$ was measured immediately

124 upon arrival to the laboratory and it was $7.2 \pm 0.1$.

\section{$125 \quad 2.3 \quad$ Disinfection by-products}

126 Samples were analysed by purge and trap (purge temperature $=30^{\circ} \mathrm{C}$, Velocity XPT Purge and

127 Trap Sample Concentrator, Teledyne Tekmar, with auto-sampler: AQUATek 70, Teledyne

128 Tekmar) coupled with a GC-MS (HP 6890 Series GC System, 5973 Mass selective detector,

129 Hewlett Packard), and the analyses were conducted as described by Hansen et al. (2012a).

130 The employed method detects the following compounds: chloroform, bromodichloromethane,

131 dibromochloromethane, dichloroacetonitrile, bromochloroacetonitrile, trichloropropanone, 
132 dichloropropanone and trichloronitromethane. The limit of detection (LOD) and limit of

133 quantification (LOQ) were expressed as $L O D=X_{b 1}+3 S_{b 1}$ and LOQ $=X_{b 1}+10 S_{b 1}$, where ' $X_{b 1}$ '

134 is the mean concentration of the blank and $\mathrm{S}_{\mathrm{b} 1}$ is the standard deviation of the blank. The LOQ

135 values for all compounds were: chloroform $(0.6 \mu \mathrm{g} / \mathrm{L})$, bromodichloromethane $(0.6 \mu \mathrm{g} / \mathrm{L})$,

136 dibromochloromethane $(0.4 \mu \mathrm{g} / \mathrm{L})$, dichloroacetonitrile $(0.6 \mu \mathrm{g} / \mathrm{L})$, bromochloroacetonitrile $(0.2$

$137 \mu \mathrm{g} / \mathrm{L})$, trichloropropanone $(1.0 \mu \mathrm{g} / \mathrm{L})$, dichloropropanone $(1.0 \mu \mathrm{g} / \mathrm{L})$, and trichloronitromethane

$138(0.6 \mu \mathrm{g} / \mathrm{L})$.

\section{$2.4 \quad$ Treatments}

\section{$140 \quad 2.4 .1 \quad$ UV treatment}

141 Treatment was conducted using a quasi-collimated beam apparatus with a doped, medium pressure lamp ( $\mathrm{P}=700 \mathrm{~W}$, ScanResearch, Denmark). To ensure constant spectra and emission output, the lamp was turned on half an hour before the experiment. Petri dishes $(350 \mathrm{~mL})$ were used as reaction vessels, while samples were maintained headspace-free and covered by a disc of quartz glass, to limit the volatilisation of the treated sample. To ensure homogeneity during irradiation, samples were mixed gently with a stirrer. The UV dose was determined according to a method described by Hansen et al. (2013b). In summary, UV exposure in the collimated beam set-up was correlated to a real flow-through system on a pool, using the removal of combined chlorine. The UV system needs $1.0 \mathrm{kWh} / \mathrm{m}^{3}$ to remove $90 \%$ of the combined chlorine. For the collimated beam set-up, required radiation time to remove $90 \%$ of the combined chlorine from the pool water was 12.3 mins. In order to compare the experimental UV dose to a realistic treatment level, the UV system in the Gladsaxe swimming pool's hot water basin was used. This system consists of 4 UV lamps using a total of $2800 \mathrm{~W}$ and operating 24 hours per day on a total pool volume of $50 \mathrm{~m}^{3}$ (Kristensen et al., 2010, 2009). Therefore, the applied electrical energy dose from UV was $1.34 \mathrm{kWh} /\left(\mathrm{m}^{3} \cdot \mathrm{d}\right)$, and so it can be calculated that the dose equivalent to 1 day of treatment is achieved after 19 minutes of radiation. To test the stability of the UV system, the removal efficiency of monochloramine was determined in the collimated beam set-up for each experiment. As monochloramine was used as an actinometer, the UV dose was 
159 recalculated for our system to correspond to $250 \mathrm{~mJ} / \mathrm{cm}^{2} \mathrm{UV}$ dose delivered per minute from a

160 low pressure UV lamp based on the data published in Li and Blatchley (2009).

161

162

\subsubsection{Ozonation}

Ozonation was achieved by adding an amount of ozone stock solution to a water sample which resulted in maximum $10 \%$ dilution of the sample and the concentrations were back calculated according to actual dilution. Ozone dosage was determined by adding a sufficient amount of potassium indigotrisulfonate and a phosphate buffer to a separate ultra-pure water sample and measuring the absorbance of the unreacted indigotrisulfonate. A detailed description can be found in Hansen et al. (2016).

\subsubsection{Chlorination and chlorine consumption}

The formation of DBPs as a result of chlorination was investigated using a standardised DBP formation assay. Similar tests have been used in other studies investigating the potential for the formation of $\mathrm{NCl}_{3}$ (Schmalz et al., 2011), THM and HAA in swimming pool water (Kanan, 2010), THM, HAN and HAA from synthetic body fluid (Hansen et al., 2012a) and particles from pools (Hansen et al., 2012b). The effect of chlorine concentration in the assay was also recently investigated by Hansen et al. (2013a). In the current study, the same approach was used to simulate chlorination in the pool after the return of UV/ozone-treated water.

Water samples were transferred to $40 \mathrm{~mL}$ glass vials after treatment in which chlorine and boric acid were added based on the chlorine consumption determined in pre-experimental tests. The aim was to have $1 \pm 0.3 \mathrm{mg} \mathrm{Cl} / \mathrm{L}$ after 24 hours at $25^{\circ} \mathrm{C}$ (measured by ABTS). Chlorination was performed in quintuplicate, with three samples used for DBP analysis and two for the determination of residual chlorine. Samples for DBP analyses were dosed with ammonium chloride solution $(50 \mathrm{mg} / \mathrm{L})$, to quench free chlorine which neither affects the already formed DBP (Kristiana et al., 2014) nor increases N-DBP formation (Hua et al., 2014). The samples were analysed the same day. 
184

185

186

187

188

189

190

191

192

193

194

\subsection{Experiments}

In the current study, laboratory batch experiments were employed, to ensure controlled experimental conditions. The control samples were chlorinated directly for DBP analysis, to analyse the formation potential of pool water without UV and ozone treatment. Control samples for UV treatment were kept in the dark by covering them with cardboard, and thus they were not exposed to UV light - thereby ensuring the same experimental conditions (temperature, retention time, stirring). Samples of the same pool water were collected on different days (between 10 and $11 \mathrm{am}$ ) and used for experiments no later than 3 hours after collection. In the figures that accompany this study, the notation comma "," separates an action; for example, $\mathrm{UV}_{2 \mathrm{~d}}, 2 \mathrm{ppm} \mathrm{O}_{3}, \mathrm{Cl}_{2}$ represents a sample treated with a UV dose of two days $\left(9.5 \mathrm{~J} / \mathrm{cm}^{2}\right)$, subsequently ozonated with a 2 ppm dosage and then finally chlorinated for 24 hours.

\subsubsection{UV treatment}

Samples of pool water were UV irradiated for times varying between 9 and 38 minutes, which is equivalent to a half-day $\left(2.1 \mathrm{~J} / \mathrm{cm}^{2}\right)$ to two-day dose $\left(9.5 \mathrm{~J} / \mathrm{cm}^{2}\right)$ of $\mathrm{UV}$ in a real treatment situation. After UV treatment, the samples were chlorinated according to Section 2.4.3.

\subsubsection{Ozonation}

Different ozone dosages were used for the range-finding experiments. Pool samples were divided into three equal subsamples which were then ozonated with 1, 2 and 4 ppm dosages and left for at least 30 min to allow ozone reactions to proceed until completion. After ozonation, the samples were chlorinated according to Section 2.4.3.

\subsubsection{Combined treatment}

The pool samples were divided into seven subsamples. One sample out of seven was taken for the control and transferred to four $40 \mathrm{~mL}$ glass vials (one for TOC and three replicates for DBPs), while the remaining six samples were UV-irradiated with a dose corresponding to two days of UV dose $\left(9.5 \mathrm{~J} / \mathrm{cm}^{2}\right)$. One sample was immediately taken for DBP analysis while the others were ozonated with range of different dosages (1, 2, 4, 7, $10 \mathrm{ppm})$ and left for at least 30 
210 min to allow ozone reactions to proceed until completion. After ozonation, samples were

211 chlorinated according to Section 2.4.3.

$212 \quad \mathbf{2 . 5 . 4} \quad$ Repeated treatment cycle

213 Pool water samples were divided into nine subsamples. The treatment cycle consisted of UV

214 treatment followed by ozonation and subsequent chlorination. To begin with, all samples were

215 UV-irradiated with a UV dose $\left(38 \mathrm{~min}, 9.5 \mathrm{~J} / \mathrm{cm}^{2}\right)$ corresponding to the average dose the water

216 get during two days. Thereafter, one sample was taken for analysis while the rest were treated

217 with an ozone dosage of $7 \mathrm{ppm}$ and left for 30 minutes to allow ozone reactions to proceed until

218 completion. After ozonation, another sample was taken for analysis while the rest were

219 chlorinated according to Section 2.4.3. Then, a third sample was taken for analysis, which

220 completed the first cycle. The remaining six samples were treated in the same order, to complete

221 two more cycles.

222

223

224

226

227

\subsection{Estimation of toxicity}

Toxicity was estimated as reported by Hansen et al. (2012a). Based on the measured concentration of the different DBPs, cyto- and genotoxicity were estimated as the sum of the concentration of each compound divided by its $\mathrm{EC}_{50}$ (Equation (1)):

$$
\text { Toxicity }=\sum_{1}^{i} \frac{\mathrm{C}_{i}}{\mathrm{EC}_{50, i}}
$$

All $\mathrm{EC}_{50}$ values were used as reported in the literature (Muellner et al., 2007; Plewa et al., 2008).

\section{Results and discussion}

Water samples from Gladsaxe swimming pool were tested, to evaluate the effect of treatment with UV followed by ozone on swimming pool water chemistry. Eleven DBPs which are usually found in swimming pool water (Chowdhury et al., 2014) were examined. However, bromoform, dibromoacetonitrile and trichloroacetonitrile were not detected, and hence they are not reported in the results. Batch experiments were conducted in the laboratory, so DBP 
235 formation results may differ from those observed over longer time scales, where pool water is

236 treated continually with UV followed by ozonation. In a real system, water does not receive UV

237 doses equivalent to several days of treatment at once, so reactions can take place between

238 chlorine and photolysis products after ozonation and when the water enters the UV chamber for

239 the second time.

\section{$240 \quad 3.1 \quad$ Effect of $\mathbf{U V}$ on reaction with chlorine}

241 Residual chlorine was measured after 24 hours' incubation, following which chlorine 242 consumption was calculated (Figure 1a). Samples treated with UV irradiation exhibited higher 243 chlorine consumption than the non UV-treated samples (dark control). Furthermore, chlorine 244 consumption increased dose-dependently following UV exposure. A similar trend was observed 245 in a recent paper (Spiliotopoulou et al., 2015). Moreover, increase in chlorine consumption due 246 to UV irradiation of pool water have been reported by Cimetiere and De Laat (2014) and Weng 247 et al. (2012).

248 The chlorinated samples were analysed for DBPs and trends were observed for the formation of 249 DBPs when the pool water was treated with different UV doses. For some DBPs, formation 250 increased initially with the lowest dose exposure, but then it did not change significantly with 251 higher doses, e.g. dichloroacetonitrile (Figure 1b), bromodichloromethane (Figure 1e) and dichloropropanone (Figure 1g). Weng et al. (2012) also reported an increase in dichloroacetonitrile formation due to UV irradiation and chlorination. Furthermore, the formation of chlorinated nitriles involves cleavage of $\mathrm{N}-\mathrm{Cl}$ bonds ( $\mathrm{Li}$ and Blatchley, 2007; Weng et al., 2012) and UV irradiation has been effective for cleavage of $\mathrm{N}-\mathrm{Cl}$ bonds ( $\mathrm{Li}$ and Blatchley, 2009; Weng and Blatchley, 2013; Weng et al., 2013, 2012). However, for other

257 DBPs formation increased dose-dependently, similar to chlorine demand, e.g. 258 dibromochloromethane (Figure 1f) and trichloropropanone (Figure 1h), where formation increased following higher UV doses but then decreased when exposed to the highest dose $\left(\mathrm{UV}_{10 \mathrm{~d}}\right)$. Another pattern was also observed in chloroform (Figure 1d) and 
261 bromochloroacetonitrile, where formation increased almost threefold with the lowest UV dose

$262\left(\mathrm{UV}_{1 / 2 \mathrm{~d}}\right)$ but then did not change with a further increase in UV dose. However, it decreased 263 when treated with the highest dose $\left(\mathrm{UV}_{10 \mathrm{~d}}\right)$. An explanation for this decrease in formation 264 during post UV chlorination could likely be due to decrease in DOC level by oxidation at very 265 high UV dose (Figure S3) and thus lower amount of precursor was available for reaction.. The 266 DOC level in $\mathrm{UV}_{10 \mathrm{~d}}$ decreased by $37 \%$ compared to the initial value (Figure S3).

267 Trichloronitromethane increased almost threefold with chlorination following treatment with the 268 lowest UV dose, but then trichloronitromethane decreased with a higher UV dose and fell to its 269 minimum level at the highest applied UV dose.

270 The amount of bromide incorporated in THM increased in the UV-treated samples compared to the dark control. Brominated DBP formation increased significantly with the lowest UV dose, and formation increased further with higher UV doses. Spiliotopoulou et al. (2015) have reported similar results and suggested that UV treatment breaks down $\mathrm{Br}$-carbon bond in large molecules (DOC), which results in brominated DBPs, as the released bromide is oxidised to $\mathrm{HOBr}$ by $\mathrm{HOCl}$ which then reacts with DOC. This is supported by that brominated THMs absorbs UV irradiation more effectively than chlorinated THM (Nicole et al., 1991) which results in faster removal of brominated compounds than chlorinated compounds during UV irradiation (Hansen et al., 2013b). Calculated cytotoxicity (Figure 1k), which was mainly attributed to dichloroacetonitrile (as this was the largest addend in the calculation according to Equation 1), increased in the samples treated with UV followed by chlorination, but the increase was not dose-dependent, whereas genotoxicity (Figure 11), which derives mainly from trichloronitromethane (contributing generally with the largest addend in the summation according to Equation 1), was highest when treated with the lowest UV dose and then decreased dose-dependently. 
285

286

287

288

289

290

291

292

293

294

295

296

297

298

299

300

301

302

303

304

305

306

307

308

309

\subsection{Effect of ozonation}

There was a significant increase in chlorine consumption, due to ozone exposure to the pool water (Figure 2a). Consumption was almost twice the amount compared to the control (DC) with the lowest ozone dosage $(1 \mathrm{mg} / \mathrm{L})$, and it increased further with higher ozone exposure. A similar increase in chlorine consumption has been reported by Hansen et al. (2016) during the chlorination of ozonated pool water. The increase is likely due to radical oxidation of precursor which can be observed during long life time of ozone where most of the ozone is removed by decomposition to radicals (Hansen et al., 2016).

There was a dosage-dependent effect observed in concentrations of most of the DBPs, in accordance with the trend in chlorine consumption. Regarding THMs, chloroform formation increased almost twofold with the lowest ozone dosage ( $1 \mathrm{mg} / \mathrm{L}$ of ozone) exposure, and it increased further with higher ozone dosages (Figure 2d). However, the formation of bromodichloromethane (Figure 2e) and dibromochloromethane (Figure 2f) increased with the initial dosage, but their concentrations remained unchanged with further increases in dosage. These results contradict the small decrease in TTHM formation potential after the ozonation of pool water reported by Glauner et al. (2005). A recent study (Hansen et al., 2016) observed that the effect of ozone on THM formation during subsequent chlorination is dependent on the characteristics of the DOC. If the DOC is mainly fresh pollutant from bathers, then ozone is consumed quickly and THM formation decreases following ozone treatment. Conversely, if the DOC is mainly "old" pollutant which has been exposed to chlorine for a long period, the DOC is less reactive with ozone, and a longer ozone lifetime and increased THM formation are observed following ozone treatment. We observed the lifetime of $2 \mathrm{mg} / \mathrm{L}$ ozone to be more than 20 mins (Figure S1, SI), which indicates that the DOC in the pool water reacted only very slowly with ozone. This fits with the increase in THM formation observed following ozone treatment. 
310 Regarding HANs, the only increase was observed following a higher ozone dosage (4 $\mathrm{mg} / \mathrm{L})$, so

311 with lower ozone dosage $(1 \mathrm{mg} / \mathrm{L}, 2 \mathrm{mg} / \mathrm{L})$ exposure there was almost no effect on the

312 formation of either dichloroacetonitrile (Figure 2b) or bromochloroacetonitrile (Figure 2c). For

313 other DBPs, the formed concentration of dichloropropanone was under the detection limit

314 (Figure $2 \mathrm{~g}$ ), while the formation pattern was quite similar to the one observed in chloroform for trichloropropanone (Figure 2h) and trichloronitromethane (Figure 2i). Increase in

316 trichloronitromethane formation during ozonation has previously been reported for pool water 317 treatment (Hansen et al., 2016) and drinking water treatment (Hoigne and Bader, 1988; Merlet 318 et al., 1985). Cytotoxicity and genotoxicity increased dosage dependently. Hence, toxicity of 319 following the ozonated swimming pool water increased. However, brominated DBP formation 320 increased minimally with the lowest ozone dosage, but it did not increase further with higher dosages.

\subsection{Combined treatment}

323 Chlorine consumption decreased when UV-treated pool water samples were exposed to the lowest ozone dosage $(1 \mathrm{mg} / \mathrm{L})$. Consumption decreased further dose-dependently and was lowest when treated with the highest ozone dosage $(10 \mathrm{mg} / \mathrm{L})$. A likely explanation for this is that the UV treatment of pool water made the DOC more reactive to chlorine (as seen in the previous section) which then reacts with ozone. Thus, when ozone reacts with the reactive DOC, reactivity is removed and lower chlorine consumption is observed.

The chlorination of UV-treated pool water samples produced the highest formation of THMs (Figure 2). However, this formation decreased when the UV-treated samples received added ozone at a low dosage $(1 \mathrm{mg} / \mathrm{L}$ of ozone $)$. In addition, the formation of chloroform reduced significantly with a lower ozone dosage added to UV-treated pool water, while the decrease was less significant with higher ozone dosages. The formation of brominated THMs

334 (bromodichloromethane, dibromochloromethane) also decreased in line with increasing ozone dosage. However, for the brominated THMs the reduction in formation was lowest at low ozone 
336 dosages and highest with high ozone dosages. At the highest ozone dosage $(10 \mathrm{mg} / \mathrm{L}) \mathrm{THM}$

337 formation was below the limit of quantification. The reason for this contradiction in the effect of

338 ozone dosage should be found in the lifetime of ozone. For the low ozone dosage, ozone was

339 consumed quickly, as it reacts with the reactive DOC induced by UV (Figure S1, SI). Bromate

340 formation is not expected with short lifetime of ozone as bromide requires ozone contact time or

341 radical exposure from decomposition of ozone to form bromate (Antoniou and Andersen, 2012).

342 Thus bromide can react with chlorine to form hypobromous acid which then forms brominated

343 DBPs (Hansen et al., 2016; Spiliotopoulou et al., 2015). At high ozone dosages, ozone saturated

344 the DOC with high reactivity to ozone, and hence a longer ozone lifetime is expected - as seen

345 in previous research (Hansen et al., 2016) which results in the oxidation of bromide to bromate.

346 A similar trend in THM formation was observed in HANs (dichloroacetonitrile,

347 bromochloroacetonitrile) and dichloropropanone. However, trichloropropanone formation could

348 not be reduced, even at the highest ozone dosage. A previous study reports that

349 trichloropropanone did not form directly following the UV treatment of pool water; rather,

350 precursor formation for trichloropropanone occurs (Spiliotopoulou et al., 2015). Based on our

351 results it appears that ozone does not react with the precursor for trichloropropanone once it is

352 formed during the UV treatment of pool water.

353 The trichloronitromethane trend was different from other DPBs, where lower ozone dosages had

354 a negligible effect on formation; however, formation increased significantly with higher ozone

355 dosages. The formation of trichloronitromethane during ozonation followed by chlorination is

356 known in drinking and pool water treatment (Hansen et al., 2016; Hoigne and Bader, 1988;

357 Merlet et al., 1985). A recent study identified primary and secondary amines as being the most

358 dominant trichloronitromethane precursors in natural water during ozonation followed by

359 chlorination (McCurry et al., 2016). In general, ozone reacts slowly with nitrogen-containing

360 compounds (Rice, 1995), which explains the lack of effect of ozone on trichloronitromethane

361 formation at lower ozone dosages, due to the very short ozone lifetime. Calculated cytotoxicity, 
362 which was mainly attributable to HANs, e.g. dichloroacetonitrile and bromochloroacetonitrile,

363 reduced significantly during the combined treatment. However, genotoxicity, which was mainly

364 caused by trichloronitromethane, increased with the combined treatment. The ozonation of UV-

365 treated pool water removed the formation of most of the DBPs except for trichloronitromethane,

366 which is the main contributor to the calculated genotoxicity of water.

367

368

\subsection{Repeated treatment cycle}

The increase in genotoxicity, due to an increase in trichloronitromethane, seems to be a problem at this stage of the combined treatment, but in the literature it has also been reported that UV treatment can photolyse trichloronitromethane (Hansen et al., 2013b). Therefore, a combined treatment experiment was performed in cycles to investigate the effect of continued treatment that would occur in a swimming pool. The experiment with repeated treatment cycles was performed with high treatment levels (two-day UV dose and $7 \mathrm{mg}$ ozone/L). This level of treatment is not realistic in a pool, but it is used herein to investigate trends in DBP formation during repeated treatment.

Chlorine consumption was measured after each treatment cycle (Figure 3a) and was found to decrease gradually in each cycle. This indicates that the remaining DOC becomes less reactive. In general, when chlorine consumption decreases, the formation of DBPs also decreases, which was also observed for the investigated DBP except for trichloropropanone. Based on the results presented in Figures 1 and 2, which are summarised in Table 1, both UV and ozone may increase the formation of trichloropropanone, and ozone dosage does not remove the precursor when added as post-UV treatment. However, trichloropropanone was removed by UV in the next treatment cycle (Figure 3h), which is in accordance with the findings in Hansen et al. (2013b). Nonetheless, it should be noted that UV removal was not enough to decrease the concentration during the three treatment cycles.

Chloroform, bromodichloromethane, dibromochloromethane and bromochloroacetonitrile all show similar patterns during the repeated treatment cycle. UV treatment increases formation 
388 potential, and the following ozone treatment decreases it. During UV treatment in the next 389 treatment cycle, bromodichloromethane, dibromochloromethane and bromochloroacetonitrile 390 decrease (Figure 3), as expected, since they previously have been found to be photolysed by UV

391 (Hansen et al., 2013b). Dichloroacetonitrile and dichloropropanone behave a little differently 392 (Figure $3 \mathrm{~b}$ and $3 \mathrm{~g}$ ), in that their formation also increased following UV treatment and decreased 393 again after ozone exposure (Table 1), but both compounds were formed during UV treatment and seemed to be removed by ozone. 
395 Trichloronitromethane exhibited a different pattern. As for the other DBPs, UV increased the

396 formation of trichloromethane during chlorination, but ozone increased it further, and thus a

397 relatively high concentration of trichloronitromethane was found after chlorination at the end of

398 a cycle. However, UV can easily photodegrade trichloronitromethane (Hansen et al., 2013b),

399 which was also observed in the following treatment cycle. For each completed treatment cycle,

400 the level of trichloronitromethane measured at the end decreased.

401 Bromine-containing DBPs were photolysed during UV treatment, and bromide was liberated

402 into the water. The following ozone mainly reacted with reactive DOC and not with the

403 bromide; thus, the bromide was oxidized by chlorine and new brominated DBPs were formed.

404 However, based on the measured brominated THMs and bromochloroacetonitrile, the results

405 indicated that fewer brominated DBPs were formed after a few repeated treatment cycles.

406 Consequently, the genotoxicity of pool water should also decrease, as brominated DBPs in

407 general are more genotoxic than their chlorinated counterparts (Muellner et al., 2007; Plewa et

408 al., 2008). As trichloronitromethane was the main contributor to the calculated genotoxicity,

409 genotoxicity follows the same pattern as trichloronitromethane and thus decreased after a few

410 repeated treatment cycles. These results indicate that continuous treatment with UV, followed

411 by ozone, could be a possible solution to reducing the amount of DBPs and thereby improving

412 water quality in swimming pools.

\section{Conclusions}

414 The treatment of swimming pool water by means of UV irradiation increased chlorine demand.

415 Furthermore, the ozonation of pre-treated UV-irradiated pool water subsequently removed

416 chlorine demand and decreased DBP formation. Combined treatment effectively reduced the

417 level of disinfection by-products in pool water except for trichloronitromethane where an

418 increase was observed. Trichloronitromethane was reduced after repeated treatment cycles and

419 thus UV/ozone treatment is predicted to improve swimming pool water quality. 


\section{Acknowledgements}

421 The authors would like to thank Scan Research A/S for making available the laboratory's UV

422 system for the study. Furthermore, we wish to thank Gladsaxe public swimming pool's staff for

423 their cooperation. Waqas A. Cheema is grateful for a funded PhD stipend provided by NUST

424 and DTU environment to support this work. 


\section{References}

Antoniou, M.G., Andersen, H.R., 2012. Evaluation of pretreatments for inhibiting bromate formation during ozonation. Environ. Technol. 33, 1747-53. doi:10.1080/09593330.2011.644586

Bader, H., Hoigné, J., 1981. Determination of ozone in water by the indigo method. Water Res. 15, 449-456. doi:10.1016/0043-1354(81)90054-3

Beyer, A., Worner, H., van Lierop, R., 2004. The use of UV for destruction of combined chlorine.

Cassan, D., Mercier, B., Castex, F., Rambaud, A., 2011. Nitrogen trichloride levels in air in chlorinated indoor swimming pools treated by medium-pressure UV radiation, in: IOA IUVA World Congress \& Exhibition, Paris. p. XIV.2-1-XIV.2-6.

Cassan, D., Mercier, B., Castex, F., Rambaud, A., 2006. Effects of medium-pressure UV lamps radiation on water quality in a chlorinated indoor swimming pool. Chemosphere $62,1507-$ 1513. doi:10.1016/j.chemosphere.2005.06.006

Chowdhury, S., Alhooshani, K., Karanfil, T., 2014. Disinfection byproducts in swimming pool: Occurrences, implications and future needs. Water Res. 53, 68-109. doi:10.1016/j.watres.2014.01.017

Cimetiere, N., De Laat, J., 2014. Effects of UV-dechloramination of swimming pool water on the formation of disinfection by-products: A lab-scale study. Microchem. J. 112, 34-41. doi:10.1016/j.microc.2013.09.014

Eichelsdörfer, D., Jandik, J., 1988. Application of ozone for treatment of swimming pool water in the federal-republic of Germany. Ozone Sci. Eng. 10, 393-403. doi:10.1080/01919518808552393

Eichelsdörfer, D., Jandik, J., 1985. Long Contact Time Ozanation For Swimming Pool Water Treatment. Ozone Sci. Eng. 7, 93-106. doi:10.1080/01919518508552328 
450 Glauner, T., Kunz, F., Zwiener, C., Frimmel, F.H., 2005. Elimination of swimming pool water disinfection by-products with advanced oxidation processes (AOPs). Acta Hydrochim. Hydrobiol. 33, 585-594.

Hamil, B., 2011. Personal communications. DEL Ozone.

Hansen, K.M.S., Albrechtsen, H.-J., Andersen, H.R., 2013a. Optimal pH in chlorinated swimming pools - balancing formation of by-products. J. Water Health 11, 465-472. doi:10.2166/wh.2013.156

Hansen, K.M.S., Spiliotopoulou, A., Cheema, W.A., Andersen, H.R., 2016. Effect of ozonation of swimming pool water on formation of volatile disinfection by-products - A laboratory study. Chem. Eng. J. 289, 277-285. doi:10.1016/j.cej.2015.12.052

Hansen, K.M.S., Willach, S., Antoniou, M.G., Mosbæk, H., Albrechtsen, H.-J., Andersen, H.R., 2012a. Effect of $\mathrm{pH}$ on the formation of disinfection byproducts in swimming pool water Is less THM better? Water Res. 46, 6399-6409. doi:org/10.1016/j.watres.2012.09.008

Hansen, K.M.S., Willach, S., Mosbæk, H., Andersen, H.R., 2012b. Particles in swimming pool filters - does $\mathrm{pH}$ determine the DBP formation? Chemosphere 87, 241-247. doi:10.1016/j.chemosphere.2012.01.003

Hansen, K.M.S., Zortea, R., Piketty, A., Vega, S.R., Andersen, H.R., 2013b. Photolytic removal of DBPs by medium pressure UV in swimming pool water. Sci. Total Environ. 443, 850856. doi:10.1016/j.scitotenv.2012.11.064

Hoigne, J., Bader, H., 1988. The formation of trichloronitromethane (chloropicrin) and chloroform in a combined ozonation/chlorination treatment of drinking water. Water Res. 22, 313-319. doi:10.1016/S0043-1354(88)90120-0

Hua, G., Kim, J., Reckhow, D.A., 2014. Disinfection byproduct formation from lignin precursors. Water Res. 63, 285-295. doi:10.1016/j.watres.2014.06.029 
Jing Li and Ernest R. Blatchley, 2007. Volatile Disinfection Byproduct Formation Resulting from Chlorination of Organic-Nitrogen Precursors in Swimming Pools. doi:10.1021/ES070871+

Kanan, A., 2010. Occurrence and formation of disinfection by-products in indoor swimming pools water. Clemson University.

Kristensen, G.H., Klausen, M.M., Andersen, H.R., 2010. Testing of different treatment technologies in swimming pools (In Danish: Afprøvning af forskellige renseteknologier på svommebade). Danish Nature Agency, Denmark. http://www.naturstyrelsen.dk/.

Kristensen, G.H., Klausen, M.M., Andersen, H.R., Erdinger, L., Lauritsen, F.R., Arvin, E., Albrechtsen, H.-J., 2009. Full scale test of UV-based water treatment technologies at Gladsaxe Sportcentre - with and without advanced oxidation mechanisms, in: The Third International Swimming Pool and Spa Conference, London, March.

Kristiana, I., Lethorn, A., Joll, C., Heitz, A., 2014. To add or not to add: The use of quenching agents for the analysis of disinfection by-products in water samples. Water Res. 59, 90-98. doi:10.1016/j.watres.2014.04.006

Lee, J., Jun, M.-J., Lee, M.-H., Lee, M.-H., Eom, S.-W., Zoh, K.-D., 2010. Production of various disinfection byproducts in indoor swimming pool waters treated with different disinfection methods. Int. J. Hyg. Environ. Health 213, 465-474. doi:10.1016/j.ijheh.2010.09.005

Li, J., Blatchley III, E.R., 2009. UV photodegradation of inorganic chloramines. Environ. Sci. Technol. 43, 60-65. doi:10.1021/es8016304

Liviac, D., Wagner, E.D., Mitch, W.A., Altonji, M.J., Plewa, M.J., 2010. Genotoxicity of water concentrates from recreational pools after various disinfection methods. Environ. Sci. Technol. 44, 3527-3532.

McCurry, D.L., Quay, A., Mitch, W.A., 2016. Ozone Promotes Chloropicrin Formation by 
Oxidizing Amines to Nitro Compounds. Environ. Sci. Technol. acs.est.5b04282. doi:10.1021/acs.est.5b04282

Merlet, N., Thibaud, H., Dore, M., 1985. Chloropicrin formation during oxidative treatments in the preparation of drinking water. Sci. Total Environ. 47, 223-228. doi:10.1016/00489697(85)90332-8

Muellner, M.G., Wagner, E.D., Mccalla, K., Richardson, S.D., Woo, Y.T., Plewa, M.J., 2007. Haloacetonitriles vs. regulated haloacetic acids: Are nitrogen-containing DBFs more toxic? Environ. Sci. Technol. 41, 645-651. doi:10.1021/es0617441

Nicole, I., De Laat, J., Dore, M., Duguet, J.P., Suty, H., 1991. Etude de la degradation des trihalomethanes en milieu aqueux dilue par irradiation UV - determination du rendement quantique de photolyse a 253,7 nm. Environ. Technol. 12, 21-31. doi:10.1080/09593339109384978

Pinkernell, U., Nowack, B., Gallard, H., von Gunten, U., 2000. Methods for the photometric determination of reactive bromine and chlorine species with ABTS. Water Res. 34, 43434350. doi:10.1016/S0043-1354(00)00216-5

Plewa, M.J., Wagner, E.D., Muellner, M.G., Hsu, K.M., Richardson, S.D., 2008. Comparative mammalian cell toxicity of N-DBPs and C-DBPs, in: Karanfil, T., SW, K., Xie, Y. (Eds.), Disinfection By-Products in Drinking Water: Occurrence, Formation, Helth Effects, and Control, Acs Symposium Series. American Chemical Society, Washington, DC, pp. 3650.

Rice, R.G., 1995. Chemistries of ozone for municipal pool and spa water treatment. J. Swim. pool spa Ind. 1, 25-44.

Richardson, S.D., DeMarini, D.M., Kogevinas, M., Fernandez, P., Marco, E., Lourencetti, C., Ballesté, C., Heederik, D., Meliefste, K., McKague, A.B.B., Marcos, R., Font-Ribera, L., Grimalt, J.O., Villanueva, C.M., 2010. What's in the pool? A comprehensive identification 
of disinfection by-products and assessment of mutagenicity of chlorinated and brominated swimming pool water. Environ. Health Perspect. 118, 1523-1530. doi:10.1289/ehp.1001965

Richardson, S.D., Plewa, M.J., Wagner, E.D., Schoeny, R., DeMarini, D.M., 2007. Occurrence, genotoxicity, and carcinogenicity of regulated and emerging disinfection by-products in drinking water: A review and roadmap for research. Mutat. Res. - Rev. Mutat. Res. 636, 178-242. doi:10.1016/j.mrrev.2007.09.001

Schmalz, C., Frimmel, F.H., Zwiener, C., 2011. Trichloramine in swimming pools - Formation and mass transfer. Water Res. 45, 2681-2690. doi:10.1016/j.watres.2011.02.024

Shah, A.D., Mitch, W.A., 2012. Halonitroalkanes, Halonitriles, Haloamides, and NNitrosamines: A Critical Review of Nitrogenous Disinfection Byproduct Formation Pathways. Environ. Sci. Technol. 46, 119-131. doi:10.1021/es203312s

Soltermann, F., Widler, T., Canonica, S., von Gunten, U., 2014. Photolysis of inorganic chloramines and efficiency of trichloramine abatement by UV treatment of swimming pool water. Water Res. 56, 280-291. doi:10.1016/j.watres.2014.02.034

Spiliotopoulou, A., Hansen, K.M.S., Andersen, H.R., 2015. Secondary formation of disinfection by-products by UV treatment of swimming pool water. Sci. Total Environ. 520, 96-105. doi:10.1016/j.scitotenv.2015.03.044

Teo, T.L.L., Coleman, H.M., Khan, S.J., 2015. Chemical contaminants in swimming pools: Occurrence, implications and control. Environ. Int. 76, 16-31. doi:10.1016/j.envint.2014.11.012

von Gunten, U., 2003. Ozonation of drinking water: part I. Oxidation kinetics and product formation. Water Res. 37, 1443-67. doi:10.1016/S0043-1354(02)00457-8

von Sonntag, C., von Gunten, U., 2012. Chemistry of Ozone in Water and Wastewater Treatment: From Basic Principles to Applications, 1st ed. IWA Publishing. 
549 Wang, W., Qian, Y., Boyd, J.M., Wu, M., Hrudey, S.E., Li, X.F., 2013. Halobenzoquinones in 550 swimming pool waters and their formation from personal care products. Environ. Sci. Technol. 47, 3275-3282. doi:10.1021/es304938x

552

Weng, S., Blatchley, E.R., 2013. Ultraviolet-Induced Effects on Chloramine and Cyanogen Chloride Formation from Chlorination of Amino Acids. Environ. Sci. Technol. 47, 42694276. doi:10.1021/es400273w

Weng, S.C., Li, J., Blatchley, E.R., 2012. Effects of UV254 irradiation on residual chlorine and DBPs in chlorination of model organic-N precursors in swimming pools. Water Res. 46, $2674-2682$.

Weng, S.C., Li, J., Wood, K. V., Kenttämaa, H.I., Williams, P.E., Amundson, L.M., Blatchley, E.R., 2013. UV-induced effects on chlorination of creatinine. Water Res. 47, 4948-4956. doi:10.1016/j.watres.2013.05.034

White, G.C., 1992. Handbook of chlorination and alternative disinfectants. Van Nostrand Reinhold, New York.

World Health Organisation, 2006. Guidelines for safe recreational water environments. Volume 2, Swimming pools and similar environments. World Health Organization, WHO Press, Geneva, Switzerland.

Zare Afifi, M., Blatchley, E.R., 2016. Effects of UV-based treatment on volatile disinfection byproducts in a chlorinated, indoor swimming pool. Water Res. 105, 167-177. doi:10.1016/j.watres.2016.08.064 
Figure 1. Effect of the UV treatment of swimming pool water on chlorine consumption, DBP formation potential and toxicity. j) The red area and the \% indicate the amount of bromine incorporated in the total trihalomethane. The dotted line indicates the limit of quantification (LOQ), whereas the error bar indicates the range of measured values.

Figure 2. Effect of ozonation and combined treatment of swimming pool water on chlorine consumption, DBP formation potential and toxicity. j) The red area and the \% indicate the amount of bromine incorporated in the total trihalomethane. The dotted line indicates the limit of quantification (LOQ), whereas the error bar indicates the range of measured values.

Figure 3. Effect of repeated combined treatment of swimming pool water in a cycle on chlorine consumption, DBPs formation potential and toxicity. j) The red area and the \% indicate the amount of bromine incorporated in the total trihalomethane. The dotted line indicates the limit of quantification (LOQ) whereas the error bar indicates the range of measured values. 
Table 1. Summary of the effect of ozone and UV on the formation of DPB during chlorination and on the DBPs themselves.

Bold indicates a high effect.

DBP formation during chlorination

DBP
Effect on the DBPs themselves after treatment

\begin{tabular}{lcccc} 
& Increase & Decrease & Increase & Decrease \\
\hline Dichloroacetonitrile & $\mathbf{U V}, \mathrm{O}_{3}$ & $\mathrm{O}_{3}$ & $\mathrm{UV}^{*}$ & $\mathrm{O}_{3}$ \\
Bromochloroacetonitrile & $\mathbf{U V}, \mathrm{O}_{3}$ & $\mathrm{O}_{3}$ & & $\mathrm{UV}$ \\
Chloroform & $\mathbf{U V}, \mathrm{O}_{3}$ & $\mathrm{O}_{3}$ & - & - \\
Bromodichloromethane & $\mathbf{U V}, \mathrm{O}_{3}$ & $\mathrm{O}_{3}$ & $\mathrm{UV}$ \\
Dibromochloromethane & $\mathbf{U V}, \mathrm{O}_{3}$ & $\mathrm{O}_{3}$ & - & $\mathbf{U V}$ \\
Dichloropropanone & $\mathbf{U V}, \mathrm{O}_{3}$ & $\mathrm{O}_{3}$ & $\mathrm{UV}^{*}$ & $\mathrm{O}$ \\
Trichloropropanone & $\mathbf{U V}, \mathrm{O}_{3}$ & - & - & $\mathrm{UV}$ \\
Trichloronitromethane & $\mathrm{UV}, \mathbf{O}_{3}$ & - & - & $\mathbf{U V}$ \\
\hline
\end{tabular}

* Confirmed in Spiliotopoulou et al. (2015) 

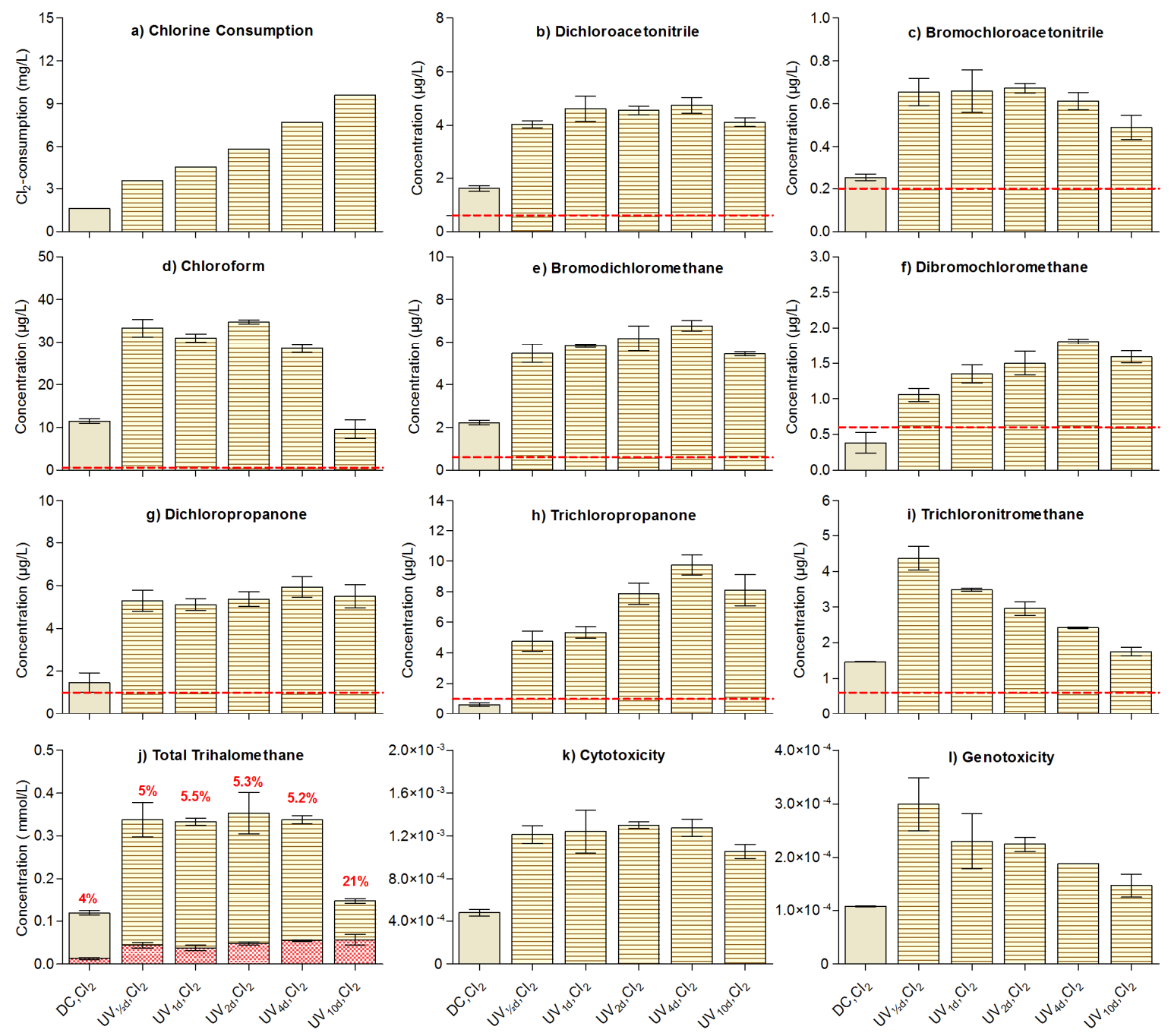

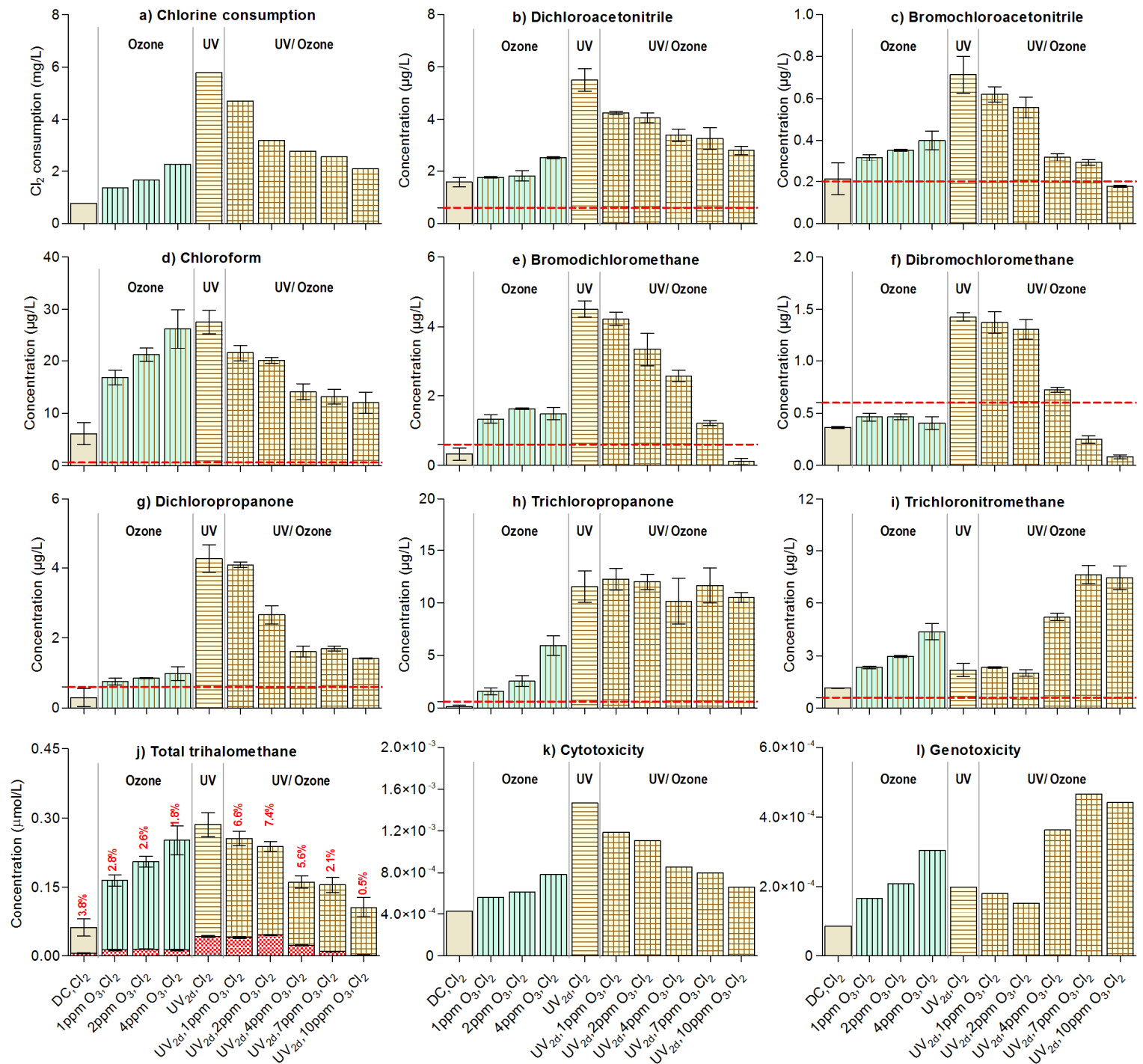

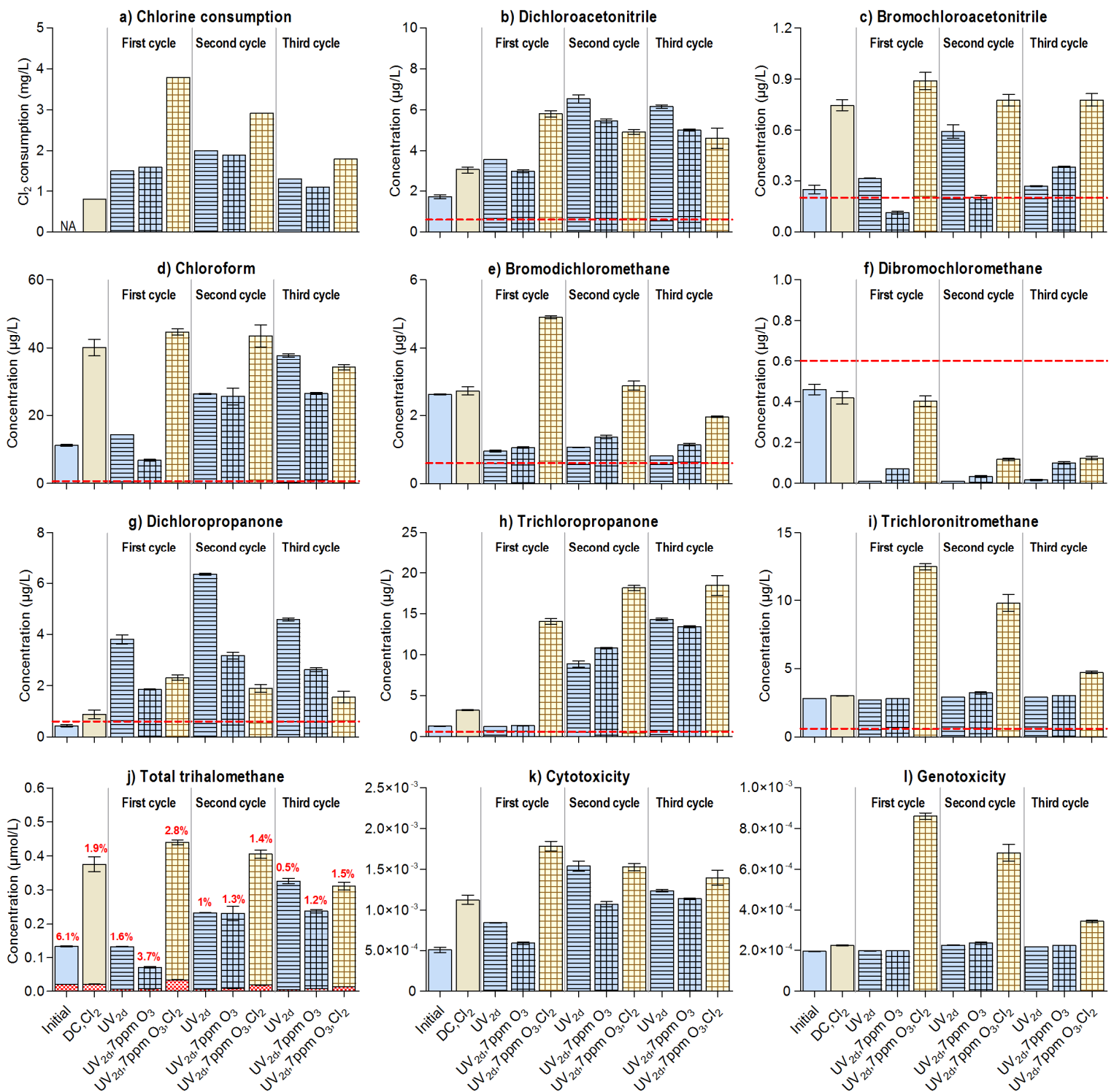


\section{Highlights}

- UV treatment increased the reactivity of pool water to both chlorine and ozone

- Ozonation of UV-treated water decrease chlorine reactivity

- Genotoxic trichloronitromethane formed by ozonation was removed with UV treatment

- Continuous UV/ozone treatment decreases chlorine by-product formation

- Continuous UV/ozone treatment predicted to improve chlorinated pool water quality 